http://dx.doi.org/10.5007/1980-3532.2012n8p54

\title{
O partido político em Florestan Fernandes
}

\section{The political party in Florestan Fernandes}

\author{
Michel Goulart da Silva \\ Doutorando em História pela Universidade Federal de Santa Catarina (UFSC) \\ Técnico em Assuntos Educacionais do Instituto Federal Catarinense (IFC) \\ michelgsilva@yahoo.com.br
}

\begin{abstract}
Resumo: Discute-se neste artigo a concepção de partido defendida por Florestan Fernandes, principalmente na década de 1980. Na primeira parte expõe-se a teoria da revolução defendida pelo sociólogo e sua estratégia de socialismo. Numa segunda parte explora-se a tese de movimento socialista defendida por Florestan Fernandes no contexto de rearticulação da esquerda, no final da década de 1970. Na segunda parte são abordadas as teses defendidas pelo sociólogo acerca do Partido dos Trabalhadores (PT), principalmente as suas contribuições apresentadas no primeiro congresso do partido, em 1992.
\end{abstract}

Palavras-chave: Florestan Fernandes. Marxismo. Partido político. Socialismo. Revolução burguesa.

\begin{abstract}
It is argued in this paper the design of party defended by Florestan Fernandes, especially in the 1980s. The first part presents the theory of revolution advocated by sociologist and exit strategy of socialism. The second part discusses the thesis defended by the socialist movement in the context of Florestan Fernandes rearticulation left in the late 1970s. Finally, we discuss the theses defended by sociologist about the Workers Party (PT), especially the theses presented at the first party congress in 1992.
\end{abstract}

Keywords: Florestan Fernandes; Marxism; Political party; Socialism; Bourgeois revolution.

Originais recebidos em: 26/11/2012

Aceito para publicação em: 04/02/2013

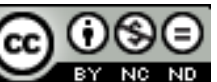
Comercial-Vedada a criação de obras derivadas 3.0 Unported License. 
O sociólogo Florestan Fernandes foi um dos mais importantes intelectuais marxistas brasileiros. Para além de sua produção acadêmica, que reúne contribuição decisiva para a sociologia no Brasil, Florestan Fernandes também elaborou aportes fundamentais para o pensamento socialista e para a práxis da esquerda, abordando temas como a revolução burguesa, a atuação política dos intelectuais e a organização política dos trabalhadores.

Essa última questão nos interessa mais de perto neste artigo. Quando se pensa na relação entre Florestan Fernandes e a questão do partido político, a primeira lembrança passa pela sua atuação no Congresso Nacional como deputado constituinte pelo Partido dos Trabalhadores (PT). Contudo, a relação partidária de Florestan Fernandes não se resume aos seus últimos anos de vida, no PT, de cujo primeiro congresso participou ativamente, em 1992. Décadas antes, entre 1943 e 1953, Florestan Fernandes atuou em uma pequena organização trotskista, o Partido Socialista Revolucionário (PSR), surgido como oposição à ditadura de Getúlio Vargas. Essa organização clandestina, produto das crises e cisões das primeiras gerações trotskistas no Brasil, influiu de forma bastante marcante na formação teórica de Florestan Fernandes. ${ }^{1}$

Este artigo procura, entendendo Florestan Fernandes como intelectual orgânico do movimento socialista brasileiro, analisar suas elaborações a respeito da questão do partido, nos diferentes contextos em que se defrontou com ela. Para tanto, trabalha-se essa discussão nos marcos tanto da teoria marxista mais geral como das contribuições acerca da revolução desenvolvidas pelo próprio Florestan Fernandes. Também são discutidas neste artigo algumas das contribuições do sociólogo aos debates realizados pelas esquerdas no período final da ditadura, especialmente suas formulações em relação ao PT.

\section{Marxismo e revolução em Florestan Fernandes}

Embora Florestan Fernandes também tenha conhecido a obra de Karl Marx nos meios acadêmicos, seu contato mais sistemático com o marxismo não se deu na universidade, dominada pelo funcionalismo na década de 1940. Segundo o sociólogo, ele deve essa aproximação com o marxismo a sua militância nas fileiras do Partido

\footnotetext{
${ }^{1}$ Para uma descrição das primeiras gerações do trotskismo no Brasil, Cf. Coggiola (2006, p. 397-416).

Em Debat: Rev. Dig., ISSNe 1980-3532, Florianópolis, n. 8, p. 54-68, jul-dez, 2012.
} 
Socialista Revolucionário (PSR), no qual começou a militar em 1943, e à influência de Hermínio Sacchetta, líder do movimento trotskista (COGGIOLA, 1995, p. 11). Embora o PSR tenha se dissolvido em 1953, essa aproximação com o trotskismo influenciou o marxismo desenvolvido pelo sociólogo, como se percebe em diferentes momentos de sua trajetória política e intelectual.

Nesse sentido, pode-se ressaltar a utilização por Florestan Fernandes da teoria da revolução permanente e do conceito de desenvolvimento desigual e combinado, claramente influenciado pelas teses de Leon Trotsky. No que se refere ao desenvolvimento desigual e combinado, o revolucionário russo afirma:

a desigualdade do ritmo, que é a lei mais geral do processus histórico, evidencia-se com maior vigor e complexidade nos destinos dos países atrasados. Sob o chicote das necessidades externas, a vida retardatária vê-se na contingência de avançar aos saltos. Desta lei universal da desigualdade dos ritmos decorre outra lei que, por falta de denominação apropriada, chamaremos de lei do desenvolvimento combinado, que significa aproximação das diversas etapas, combinação das fases diferenciadas, amálgama das formas mais arcaicas com as mais modernas (TROTSKY, 1978, p. 25).

Nesse aspecto, Trotsky chama a atenção, por um lado, para os diferentes ritmos de desenvolvimento do capitalismo dos países. Por outro, afirma que esses países de desenvolvimento desiguais se relacionam na economia internacional, apesar dos diferentes ritmos de suas economias, criando relações de dependência entre eles. Portanto, na economia mundial relacionam-se países mais industrializados e outros onde ainda predominam formas de organização econômica baseadas na agricultura, gerando situações de dominação e exploração entre os países. Segundo o economista Ernest Mandel (1982, p. 14, grifos do autor),

o modo de produção capitalista não se desenvolveu em meio a um vácuo, mas no âmbito de uma estrutura sócio-econômica específica, caracterizada por diferenças de grande importância. (...) As formações sócio-econômicas específicas - as "sociedades burguesas" e as economias capitalistas - que surgiram nessas diferentes áreas no decorrer dos séculos (...) abrangem o capitalismo "concreto", reproduzem em formas e proporções variáveis uma combinação de modos de produção passados e presentes, ou, mais precisamente, de estágios variáveis, passados e sucessivos, do atual modo de produção.

Florestan Fernandes incorporou esses referenciais teóricos e analíticos à sua teoria para compreender as relações históricas de produção econômica no Brasil, ao afirmar:

em sua formulação sobre o desenvolvimento desigual e combinado estabeleceu que, em sociedades atrasadas, as classes trabalhadoras e destituídas podiam acelerar o processo histórico, desempenhando as tarefas negligenciadas ou repelidas pelas classes proprietárias. Em consequência, 
cabia-lhes desencavar processos históricos latentes à ordem existente, infundir-lhes maior velocidade e encetar a criação de uma sociedade nova (FERNANDES, 1995, p. 119-20).

Em sua principal obra, A revolução burguesa no Brasil, originalmente publicada em 1975, o sociólogo aponta que o padrão de desenvolvimento do capitalismo no Brasil se caracteriza a partir de uma dupla polarização, que se constitui internamente por meio da articulação entre o setor arcaico ao setor moderno (ou urbano-comercial e industrial) e externamente pela articulação entre o complexo agrário-exportador interno e as economias capitalistas centrais (FERNANDES, 2005, p. 283). Na mesma obra o sociólogo descreve de forma detalhada esse processo de desenvolvimento, procurando polemizar com as perspectivas que apontam para um caminho único do desenvolvimento capitalista:

o que a parte dependente da periferia 'absorve' e, portanto, 'repete' com referência aos 'casos clássicos', são traços estruturais e dinâmicos essenciais, que caracterizam o que Marx designava como uma economia mercantil, a mais-valia relativa etc. e a emergência de uma economia competitiva diferenciada ou de uma economia monopolista articulada etc. Isso garante uniformidades fundamentais, sem as quais a parte dependente da periferia não seria capitalista e não poderia participar de dinamismos de crescimento ou de desenvolvimento das economias capitalistas centrais. No entanto, a essas uniformidades - que não explicam a expropriação capitalista inerente à dominação imperialista e, portanto, a dependência e o subdesenvolvimento -, se superpõem diferenças fundamentais, que emanam do processo pelo qual o desenvolvimento capitalista se torna dependente, subdesenvolvido e imperializado, articulando no mesmo padrão as economias capitalistas centrais e as economias capitalistas periféricas. Em um sistema de notação marxista, é a estas diferenças (e não àquelas uniformidades) que cabe recorrer, para explicar a variação essencial e diferencial, isto é, o que é típico da transformação capitalista e da dominação burguesa sob o capitalismo dependente. Só assim se pode colocar em evidência como e por que a Revolução Burguesa constitui uma realidade histórica peculiar nas nações capitalistas dependentes e subdesenvolvidas (FERNANDES, 2005, p. 339340).

Nesse processo de desenvolvimento econômico, combinam-se a transformação capitalista e a dominação burguesa, expressa tanto pelas contradições internas de classe como pela relação entre os diferentes países. Contudo, segundo Florestan Fernandes (2005, p. 339-340),

essa combinação se processa em condições econômicas e histórico-sociais específicas, que excluem qualquer probabilidade de 'repetição da história' ou de 'desencadeamento automático' dos pré-requisitos do referido modelo democrático-burguês.

Florestan Fernandes rejeita os esquemas prontos, presentes entre numerosos teóricos marxistas do período, que previam sequências fixas do modo de produção para o desenvolvimento da sociedade ou que apontavam para a impossibilidade de se pensar em socialismo na sociedade brasileira. Nesse ponto, o sociólogo também se aproxima de 
Trotsky, na medida em que este, em sua época, também enfrentou os dogmas estabelecidos acerca da revolução, apontando para a necessidade de a revolução socialista superar as tarefas não realizadas pela revolução burguesa na Rússia. Além disso, assim como Trotsky, Florestan Fernandes apontou para as particularidades do desenvolvimento econômico, que se daria de forma diferente dos esquemas clássicos, colocando para os revolucionários, em seu contexto, tarefas diferentes daquelas a que se propunham.

Expressando com mais força suas afinidades com a teoria trotskista, em meados da década de 1980, convidado a sistematizar suas idéias a respeito do conceito de revolução, Florestan Fernandes dialogou de forma próxima com outra tese fundamental de Leon Trotsky, sistematizada na teoria da revolução permanente. Entre as teses presentes nessa teoria, afirmava-se, primeiro, que nos países de capitalismo dependente as burguesias não liderariam um processo de transformações revolucionárias liberalburguesa, pois, desde sua formação até a sua consolidação como "donos do poder", essas classes teriam se mantido associadas ao capital externo. Segundo, que as "revoluções nacionais", para não se tornarem "revoluções interrompidas", teriam que avançar para processos socialistas que, mesmo assumindo bandeiras democráticoburguesas, deveriam ser dirigidos pelos próprios trabalhadores. Segundo o sociólogo,

\begin{abstract}
o proletariado não poderia pretender desempenhar as tarefas revolucionárias da burguesia e funcionar como um fator de compensação histórica. Isso seria pueril. A revolução dentro da ordem é meramente instrumental e conjuntural para o proletariado, ligando-se à necessidade histórica de proteger e acelerar a constituição da classe como classe em si, capaz de tomar em suas mãos o seu desenvolvimento independente. A partir de certo nível, o proletariado força a mudança de qualidade da "guerra civil oculta", exige que as reivindicações socialistas mudem de teor, pondo em cheque a supremacia burguesa e o poder político da burguesia. O que quer dizer que, desse nível em diante, o proletariado terá de hostilizar todas as criações do capitalismo; sua relação com a revolução burguesa mudará de qualidade, porque e, então passará a importar-se em como passar da "guerra civil oculta" para a "guerra civil aberta", ou seja, a derrubada da ordem e a constituição de uma democracia proletária (FERNANDES, 2007, p. 116).
\end{abstract}

Essas formulações de Florestan Fernandes encontram relação com as elaborações dos trotskistas brasileiros, desde o início da década de 1930, e as contribuições teóricas desenvolvidas pelo PSR, liderado por Hermínio Sachetta. Em artigo produzido na década de 1950, apresentado como curso de formação, Sachetta apresenta algumas das bases teóricas que seriam apropriadas nas teses posteriormente desenvolvidas por Florestan Fernandes. Segundo Sachetta (2007, p. 33), 
contra o domínio imperialista; de um lado porque a unidade orgânica da economia mundial faz dessa burguesia um parente pobre do capital financeiro e, de outro lado, porque muito mais que ao imperialismo a que, em parte, está submetida, a burguesia teme seu próprio proletariado. (...) As lições dos movimentos revolucionários de nosso século, particularmente no Oriente, estão a provar que a burguesia "progressista" é um mito nefasto que vem entorpecendo de modo trágico a ação independente de classe do proletariado.

Essas afirmações de Sachetta encontram eco na produção de Florestan Fernandes, em diferentes obras. Em certo texto, o sociólogo afirma, apontando para os limites da revolução burguesa:

\begin{abstract}
No nível mais amplo, a noção de revolução tem que ser calibrada pelas classes trabalhadoras em termos das relações antagônicas entre burguesia e proletariado dentro do capitalismo da era atual. A época das revoluções burguesas já passou; os países capitalistas da periferia assistem a uma falsa repetição da história: as revoluções burguesas em atraso constituem processos estritamente estruturais, alimentados pela energia dos países capitalistas centrais e pelo egoísmo autodefensivo das burguesias periféricas. Estamos na época das revoluções proletárias e pouco importa que elas só tenham aparecido nos "elos débeis" do capitalismo. (...) Por isso as burguesias dos países centrais se organizam como verdadeiras bastilhas e promovem seu "pluralismo democrático" ou seu "socialismo democrático" como se fossem equivalentes políticos do socialismo revolucionário e do comunismo (FERNANDES, 2007, p. 61).
\end{abstract}

Em outras palavras, Florestan aponta para o papel fundamental do proletariado como classe no processo revolucionário e para os limites políticos e sociais da burguesia como agente de transformação social. Nesse sentido, conclui o sociólogo:

\begin{abstract}
A revolução em processo, que caracteriza a presença e o papel construtivo das classes trabalhadoras na história, não é só uma revolução anticapitalista e antiburguesa. Ela é uma revolução socialista, que se negará como tal na medida em que o socialismo se converter, por sua vez, em padrão de uma nova civilização, culminando em seu eixo final que desemboca no comunismo (FERNANDES, 2007, p. 63).
\end{abstract}

Em sua análise da realidade brasileira, Florestan Fernandes apontava para a necessidade histórica de uma revolução socialista, protagonizada pelo proletariado, problematizando em seus textos a atuação das organizações de esquerda. Não se tratava de fazer uma revolução burguesa e democrática, para superar estruturas semifeudais, como afirmavam outros setores marxistas, vinculados ao stalinismo. Essa perspectiva crítica ao stalinismo fica clara, por exemplo, em meados da década de 1980, quando afirmava: "O capitalismo reformado é uma balela e os que acreditam nele como 'uma forma de revolução democrática", que seja "capaz inclusive de superar o socialismo proletário, nunca tiveram quaisquer elos efetivos com as posições proletárias na luta de classes" (FERNANDES, 2007, p. 87).

Os elementos teóricos e políticos apontados aproximam o sociólogo brasileiro das teses de Leon Trotsky, ainda que não seja possível afirmar que Florestan Fernandes 
tenha sido trotskista ao longo de sua vida. ${ }^{2}$ Sua participação nesse movimento político interrompeu-se ainda na década de 1950, conforme destacado em vários relatos do próprio sociólogo (COGGIOLA, 1995, p. 11). Contudo, há convergências importantes entre os dois pensadores, principalmente levando em conta o caráter pioneiro das ideias de ambos nos contextos particulares em que atuaram política e teoricamente e, principalmente, o compromisso de ambos com a luta do proletariado.

\section{Partido e socialismo}

Florestan Fernandes discutiu a questão do partido, de um ponto de vista teórico, apenas no período final de sua carreira acadêmica e política, produzindo alguns trabalhos ao longo da década de 1980 . O primeiro trabalho a respeito dessa temática foi Movimento socialista e partidos políticos, publicado em 1980. Esse texto, produto de uma conferência realizada pelo sociólogo em 1978, foi elaborado em um contexto de reorganização da luta dos trabalhadores e de discussão de estratégias políticas. Esse era um contexto de lutas operárias e de construção do PT, no qual Florestan Fernandes via um processo de disputa pela estratégia que o partido deveria assumir, ou seja, se deveria ser apenas um "partido da ordem" que permitisse aos trabalhadores concorrerem às eleições ou também uma organização que fosse um espaço de articulação dos revolucionários na luta pelo socialismo.

Em seu texto, Florestan Fernandes tem como ponto de partida a definição de movimento socialista, apontando-o como "uma confluência das forças anticapitalistas" (FERNANDES, 1980, p. 6). Segundo o sociólogo, na sociedade capitalista surgiriam forças antagônicas ao sistema estabelecido que buscariam acabar com esse modo de produção, lutando contra o regime de classes, o Estado e o sistema de poder da burguesia. Com isso, nos termos propostos por Florestan Fernandes, o movimento socialista poderia tanto assumir uma forma "gradualista" como uma forma revolucionária. Contudo, necessariamente ele deveria constituir-se na confluência de

\footnotetext{
${ }^{2}$ Pode-se destacar outro elemento que aproximava Florestan Fernandes e Trotsky: a crítica a elementos da experiência socialista na União Soviética. Em 1989, o sociólogo escreveu no prefácio a um livro de um dirigente trotskista do PT: "O stalinismo, que não se resume nem se confunde com Stalin como indivíduo e chefe dos que herdaram o poder pós-revolucionário, correspondeu a uma desbolchevização dos sovietes e da ditadura do proletariado. Ele subiu na onda das 'deformações burocráticas', que substituíram a prioridade da revolução pela centralidade do desenvolvimento econômico com segurança e culminaram no terror com técnica de condução do Estado, de esmagamento dos adversários e de aceleração do crescimento econômico a qualquer preço" (FERNANDES, 1995, p. 191).
} 
todas as forças que se voltavam contra a ordem existente e colocavam-se ou no sentido de reformas antiburguesas dentro dessa ordem ou buscavam alimentar uma revolução contra a ordem e organizar a sociedade, a economia e o sistema de poder em novas bases. Os partidos, nesse caso, seriam "a forma de organização institucional dessas forças", ou seja, "essas forças sociais se organizam institucionalmente e é através dos partidos que se realiza a aglutinação de forças" (FERNANDES, 1980, p. 7). Segundo o sociólogo, "há partidos socialistas que contêm a sua potencialidade desagregadora e há outros que procuram maximizar essa potencialidade" (FERNANDES, 1980, p. 7-8).

Florestan Fernandes (1980, p. 8, grifos do autor) também procura analisar a situação pela qual passava o movimento socialista, apontando como diagnóstico da conjuntura: "é claro que quando o movimento socialista é fraco (...) e não tem muita densidade, a esse movimento socialista fraco correspondem, partidos socialistas débeis". Para ele, no Brasil "não temos um movimento socialista vigoroso" e, por conseguinte, "não temos também partidos socialistas fortes, que possam exercer funções agregadoras ou aglutinadoras" ou "capazes de criar uma efervescência política e coordenar movimentos de reforma social ou de revolução". Depreende-se dessa afirmação que os movimentos e partidos não se situam no vácuo, mas "são realidades históricas dentro de uma sociedade capitalista", o que faz "necessário pensar sobre qual é o grau de amadurecimento e de diferenciação do regime de classes".

Outro aspecto para o qual Florestan Fernandes chama a atenção passa pela necessidade que tem o movimento socialista de definir um inimigo comum, que "tem que ser o inimigo de classe" (FERNANDES, 1980, p. 54). Essa unidade contra um inimigo é ressaltada como uma prioridade, ou seja, devem estar "na frente" das diferenças. Diz Florestan Fernandes:

Podemos ser gradualistas, reformista; podemos ser revolucionários, ultrarevolucionários; pacientes ou impacientes. Podemos até pensar que nossas idéias criam a história, podemos pensar o que quisermos. Mas qualquer que seja o nosso grau de paciência ou de impaciência, o movimento está na frente e ele exige de todos que a definição intransigente do inimigo seja uma definição correta (FERNANDES, 1980, p. 54).

Nesse sentido, Florestan Fernandes afirma que "não se devem hostilizar os que estão nas mesmas fileiras. Devemos aprender a conviver uns com os outros, por mais difícil que isso seja como aprendizado, por mais difícil que isso seja em termos de conciliação de visões de mundo" (FERNANDES, 1980, p. 54). Para ele, nessa primeira fase é necessário "definir o inimigo de classe corretamente e lutar contra ele e não favorecer o inimigo de classe em nome de uma defesa dita 'democrática' do socialismo, 
que é uma defesa não-democrática da dominação burguesa, do imperialismo e da autocracia” (FERNANDES, 1980, p. 55, grifos do autor). Para o sociólogo, “ainda não chegou a hora em que a luta intestina, dentro do campo socialista, possa fortalecer os socialistas, dar a dianteira aos que possuem as palavras de ordem seguidas pelas massas", ou seja, seria "preciso pensar no que é comum e, depois, paralelamente ao fortalecimento prévio, pensar no que é específico de cada um” (FERNANDES, 1980, p. $55)$.

Florestan Fernandes raciocina no sentido de elaborar uma estratégia política "sem concessões à contrarrevolução e sem concessões a uma pseudodemocracia burguesa" (FERNANDES, 1980, p. 57). Para ele, é preciso compreender quais são os alvos comuns dos diferentes setores socialistas, cujos elementos comuns "são intrínsecos ao próprio socialismo" (FERNANDES, 1980, p. 57-8). Depois disso, "na medida em que se tiver êxito, as condições se modificarão, as próprias decisões da maioria tenderão a alcançar uma influência maior sobre o conjunto do movimento socialista", determinando "o que deverão ser os partidos, qual a importância relativa dos respectivos partidos em termos da influência das massas e o que cada partido terá que fazer para saturar posições de liderança nos processos reformistas ou revolucionários" (FERNANDES, 1980, p. 58). O sociólogo assim resume seu raciocínio:

\footnotetext{
Primeiro essa unificação. Depois, uma importância maior das massas, influência diferenciadora maior nas massas sobre o movimento socialista. Só então haverá um campo propício para pensar na importância relativa dos partidos em termos de opções ideológicas e políticas que variem de uns para os outros, que entrem em conflito mais ou menos irremediável. Porque aí a luta dentro do socialismo será construtiva e necessária (FERNANDES, 1980, p. 58).
}

Florestan Fernandes propõe, em um primeiro momento, uma unidade tática entre setores socialistas reformistas e revolucionários dentro um movimento amplo, que, inserido nos setores de massas do proletariado e mobilizando esses setores, possa dirigir processos políticos que coloquem os trabalhadores como personagens ativos. Para o sociólogo, seriam as experiências das massas, na luta de classes, que as fariam distanciarem-se das posições reformistas e, dessa forma, aproximar-se das organizações revolucionárias, abrindo a possibilidade para a construção de um partido político que colocasse como estratégia a superação da sociedade capitalista. Contudo, esse não seria um processo automático e simples, dependendo tanto de fatores subjetivos e objetivos, como das posições defendidas pelos setores socialistas, das formas de organização dos trabalhadores, do uso dos aparatos de repressão pelo Estado, entre outros. 
Esse elemento que se refere à inserção dos revolucionários entre as massas trabalhadoras é fundamental nas teses de Florestan Fernandes. Em um texto posterior, criticando as versões comunistas dogmáticas do stalinismo brasileiro, apontava que nas três décadas anteriores "a formação da classe se adiantou muito e os que defendem posições típicas do socialismo revolucionário e do comunismo precisam colocar-se na situação de classe dos proletários e caminhar por dentro da classe para fazer parte da vanguarda" (FERNANDES, 2007, p. 131). Para o sociólogo, essa vanguarda precisaria estar ligada organicamente às classes trabalhadoras, formando seus setores mais politizados e conscientes. Contudo, para Florestan Fernandes (2007, p. 78), “isso não quer dizer que a constituição do partido proletário revolucionário equivalia à formação de uma elite 'exterior' à massa, em típica relação de dominação com ela". 3

Florestan Fernandes também criticava a conciliação de classes propostas pelas organizações comunistas brasileiras, ao longo do século XX. Na década de 1980, procurando pensar o momento histórico em que estava inserido, o sociólogo afirmava: "a lua de mel com a burguesia, com o nacionalismo burguês, com o radicalismo burguês ou com o que se queira está acabada" (FERNANDES, 2007, p. 132). Para isso, caberia aos revolucionários "estabelecer, como parte da vanguarda da classe operária, como esta deve manejar a luta de classes com objetivos políticos bem marcados, de curto, médio e longo prazos, e para impedir que os antagonismos existentes só produzam dividendos políticos para as classes dominantes" (FERNANDES, 2007, p. 132).

\section{Florestan Fernandes e o Partido dos Trabalhadores}

Essas formulações teóricas ganharam uma nova dinâmica quando Florestan Fernandes, na condição de deputado federal, passou a intervir de forma mais intensa na vida interna do PT. Embora tenha se filiado ao partido e tenha se candidatado a deputado, manteve muitas hesitações em relação ao partido, como se percebe no relado abaixo, escrito 1989:

Na ocasião em que fiz minha inscrição, aliás, definia-se como um partido
proletário ultra-seletivo, em suas alianças e na incorporação de militantes ou
na promoção de quadros. Antes de realizar outras tarefas da classe operária,
lançou-se à conquista do poder (em escala miúda). Isso perturbou-me. A
social-democracia na Europa, do século XIX até 1910, fizera a mesma coisa.
O combate à supremacia burguesa exigia que os socialistas se lançassem à

\footnotetext{
${ }^{3}$ Segundo Florestan Fernandes, esse entendimento acerca da relação entre partido e massa encontra referência tanto em Lênin como em Marx (FERNANDES, 2007, p. 78-9).
} 
luta parlamentar, para aumentar o espaço político do movimento operário e dos sindicatos, e para difundir noções claras e críticas sobre o significado e a solução da questão operária. De outro lado, sempre estive e ainda estou confuso sobre os vários grupúsculos e tendendências do PT, a disputa acirrada de hegemonia entre eles e a ausência de vínculos políticos e ideológicos firmes, que atravessam o partido (FERNANDES, 2006, p. 243).

Sua intervenção no interior do partido evidencia-se em documentos que o sociólogo elaborou para o primeiro congresso do partido, publicados em 1991. Esses documentos visavam apresentar formulações teóricas e políticas para o partido, no sentido de contribuir para a elaboração de uma estratégia revolucionária e socialista. $\mathrm{O}$ sociólogo demonstrava essas preocupações desde a década de 1980, quando, discutindo a atuação legal dos partidos socialistas, apontava:

O grande dilema desta situação está em duas tendências que ela engendra. A "concessão da legalidade" constitui uma autorização para funcionar nos limites da ordem e para ser punido nas "transgressões". Ela implica uma tendência à domesticação política e à socialdemocratização, que deve ser repelida (ou o partido só será revolucionário na intenção e no nome). A outra está na redução drástica do espaço político para a ação revolucionária. Essa tendência vai tão longe que às vezes até a educação das bases e dos quadros no conhecimento da teoria socialista revolucionária e do comunismo, bem como dos clássicos da teoria revolucionária, é negligenciada ou evitada, largada, por assim dizer, pelo partido ao azar das circunstâncias (FERNANDES, 2007, p. 139).

No texto apresentado ao congresso do PT, entre outras questões relevantes, Florestan Fernandes aponta que, na sua trajetória, o partido "desprendeu-se quer do populismo dos partidos das classes dominantes, quer do oportunismo de partidos de esquerda, que se conformavam com os papéis de cauda da política burguesa", encaminhando-se no sentido "de uma posição de luta que refutava o socialismo burocrático, a ditadura militar, os artifícios da burguesia reacionária ou conservadora e os propósitos espoliativos do imperialismo" (FERNANDES, 1991, p. 11). Segundo o sociólogo, "o PT eclodiu como a via que poderia unir os trabalhadores e seus aliados orgânicos nas várias batalhas simultâneas que deveriam enfrentar para que brotasse uma República democrática e a conquista do socialismo não se restringisse a mera retórica" (FERNANDES, 1991, p. 11).

Mas esse partido que surgiu impelido pelas mobilizações dos trabalhadores "contra a ordem" ganhou outros contornos, nas disputas políticas do Brasil e em uma conjuntura de crise da revolução e da estratégia socialista. Nesse contexto, "o PT transpôs a divisão que vai da transformação capitalista da ordem para a revolução dentro da ordem" (FERNANDES, 1991, p. 65). Efetivamente, na luta por dentro do capitalismo, o partido conseguiu arrancar conquistas para os trabalhadores, reformas 
que melhoraram aspectos das condições de vida, por meio, por exemplo, do projeto apresentado à Assembleia Nacional Constituinte. O partido, segundo Florestan Fernandes, se ocupou pouco do conjunto de tarefas políticas que desembocam na revolução contra a ordem, ou seja, que poderia colocar a superação do capitalismo. Para o sociólogo,

o partido colocou-se no que se poderia designar como compasso de espera, apesar do clamor dos oprimidos e das exigências da sua extrema esquerda. Nota-se claramente, entretanto, que ele se depara com um dilema político: ou se conforma com as estritas possibilidades liberais e social-democráticas de transformação da ordem e da revolução dentro da ordem, ou avança, pela aceleração da história, da ocupação de poder para a conquista do poder, desvendando a verdadeira face de um partido revolucionário (FERNANDES, 1991, p. 67-8).

Naquele contexto, colocava-se uma situação histórica bastante particular, em que, segundo o sociólogo, o PT deveria optar pela estratégia a adotar, se reformista ou revolucionária. Florestan Fernandes assim formulava a questão: "embarcar na ânsia modernizadora das elites 'neoliberais' nativas e estrangeiras ou romper a estabilidade da ordem para forjar uma Nação e estabelecer circuitos de ida e volta entre ela, a sociedade civil e o estado" (FERNANDES, 1991, p. 77-8). Para o sociólogo,

as soluções que se originam dos diferentes grupos de tarefas políticas do PT e sua força relativa, proveniente da centralização do poder real das classes trabalhadoras e seus aliados orgânicos, impõem que toda a esquerda se entenda como condição número 1 para proceder ao desmoronamento da sociedade burguesa e da civilização capitalista (FERNANDES, 1991, p. 80).

Florestan Fernandes, em texto escrito poucos anos antes, também refletia acerca de uma estratégia socialista para o partido. Segundo o sociólogo, “o PT não pode repetir os erros danosos do dogmatismo, e, se puder, deve evitar a todo o custo os erros ainda mais graves do oportunismo e das ilusões utópicas ou românticas" (FERNANDES, 2006, p. 241). Naquele contexto, o PT seria, no seu entendimento, o principal representante dos trabalhadores, ou seja, seria o responsável pela direção política da classe. Florestan Fernandes afirmava que cabia aos trabalhadores "destruir a classe e o regime de classes" e "conduzir transição para o socialismo", considerando-se que "a conquista do poder tem de situar-se no momento certo, e não artifício para resolver, dentro do capitalismo e para o capitalismo, os problemas e os dilemas sociais que a burguesia não consegue enfrentar" (FERNANDES, 2006, p. 241). Diante do dilema entre a estratégia de reforma, afirmava o sociólogo:

o socialismo comprometido com a democracia burguesa ainda é uma forma de reprodução do sistema capitalista de poder. A revolução proletária volta-se para a emancipação coletiva dos trabalhadores pelos próprios trabalhadores. 
Ou o PT decifra a solução correta dessa necessidade histórica na cena brasileira ou ele engrossará as fileiras dos partidos reformistas imantados à 'reforma capitalista do capitalismo', ao 'capitalismo melhorado' ou ao 'capitalismo do bem-estar social'. Penso ser esta a principal resposta às indagações, às esperanças e às convicções que nos lançam, dentro do PT, à luta pelo socialismo proletário e revolucionário (FERNANDES, 2006, p. 241).

Como se pôde perceber com o passar dos anos, especialmente por meio das administrações encabeçadas ou apoiadas pelo PT, o partido optou pelo caminho das reformas do sistema capitalista. Passado a derrota no processo eleitoral de 1989 e a expulsão das correntes mais à esquerda, o partido seguiu o rumo de uma política pragmática e conservadora da ordem burguesa, afastando-se de qualquer perspectiva de transformação social por meio da revolução socialista. Embora não tenha feito uma crítica explícita à política reformista assumida pelo PT, Florestan Fernandes alertou, após a derrota eleitoral de 1989, para o processo de social-democratização do partido, ao privilegiar a participação de seus militantes e dirigentes nas estruturas de poder do Estado (FERNANDES, 2006, p. 249).

\section{Considerações finais}

Percebe-se, portanto, que as análises de Florestan Fernandes a respeito da questão do partido estão fortemente marcadas pela influência leninista, com as quais tomou contato possivelmente em sua passagem pelo PSR trotskista, nas décadas de 1940 e 1950. Essa influência, em primeiro lugar, está na postura de pensar esse tema não como abstração teórica, mas realizando análises concretas de situações concretas, verificando, entre outros fatores, a dinâmica da luta de classes em nível nacional e internacional, a situação do movimento operário no país e a dinâmica dos grupos que compõem a esquerda socialista.

Em segundo lugar, percebe-se a influência leninista na medida em que Florestan Fernandes aponta para a necessidade de constituir uma vanguarda, um setor consciente, enfim, um núcleo que olhe a situação concreta e proponha ações políticas concretas no sentido da transformação social. Nesse caso, rejeitando a tradição stalinista e aproximando-se das correntes que combateram a burocratização do marxismo, como o trotskismo, Florestan Fernandes não pensa essa vanguarda partidária como apartada das massas, mas como sua parte orgânica. 
Um dos elementos discutidos nesse artigo foi o vínculo de Florestan Fernandes com o PT, atuando como parlamentar. Conforme é possível perceber por seus textos, havia no sociólogo a clareza de que aquele não era um partido revolucionário pronto e acabado, mas que nele conviviam táticas e estratégias diversas, revolucionárias e reformistas, em permanente disputa. O sociólogo procurou, enquanto militante partidário, contribuir no sentido de fortalecer a estratégia revolucionária, para isso dando grande importância, primeiro, para uma discussão densa acerca de transformação radical da sociedade e, segundo, chamando a atenção insistentemente para a necessidade de se estudar o marxismo como forma de melhor compreender a realidade.

Por fim, destaca-se que Florestan Fernandes está discutindo a questão do partido, para além de uma análise sociológica, como forma de intervenção em conjunturas que são particulares, colocando-se como sujeito político que aponta sua militância para uma estratégica clara: a revolução socialista. Se há a necessidade de fazer mediações, construir unidades temporárias ou disputar o congresso de um partido, não importa. Para ele, o centro de todo o debate é como fazer com que os trabalhadores superem o capitalismo e construam uma nova sociedade, que, em seu entendimento, deveria ser uma sociedade socialista.

\section{Referências}

COGGIOLA, Osvaldo. Florestan Fernandes e o socialismo. In: FERNANDES, Florestan. Em busca do socialismo: últimos escritos e outros textos. São Paulo: Xamã, 1995.

COGGIOLA, Osvaldo. Historia del trotskismo en Argentina y América latina. Buenos Aires: RyR, 2006.

FERNANDES, Florestan. Em busca do socialismo: últimos escritos e outros textos. São Paulo: Xamã, 1995.

Movimento socialista e partidos políticos. São Paulo: Hucitec, 1980.

O que é revolução. In: Clássicos sobre a revolução brasileira. São Paulo:

Expressão Popular, 2007. 
FERNANDES, Florestan. Pensamento e ação: o PT e os rumos do socialismo. $2^{\mathrm{a}}$ ed. São Paulo: Globo, 2006.

O PT em movimento. São Paulo: Autores Associados, 1991.

A Revolução Burguesa no Brasil. $5^{\text {a }}$ ed. São Paulo: Globo, 2005.

MANDEL, Ernest. O capitalismo tardio. São Paulo: Abril Cultural, 1982.

SACHETTA, Hermínio. O trotskismo. In: TROTSKY, Leon. A revolução permanente. São Paulo: Expressão Popular, 2007.

TROTSKY, Leon. A história da revolução russa. $3^{\text {a }}$ ed. Rio de Janeiro: Paz e Terra, 1978. 3v. 